Article

\title{
Ethanol Production from Olive Stones through Liquid Hot Water Pre-Treatment, Enzymatic Hydrolysis and Fermentation. Influence of Enzyme Loading, and Pre-Treatment Temperature and Time
}

\author{
Manuel Cuevas ${ }^{1,2, *(\mathbb{D})}$, Juan F. García Martín ${ }^{2,3, * \mathbb{D}}$, Vicente Bravo ${ }^{4}$ and Sebastián Sánchez ${ }^{1,2}$ \\ 1 Department of Chemical, Environmental and Materials Engineering, Campus 'Las Lagunillas', \\ University of Jaén, 23071 Jaén, Spain; ssanchez@ujaen.es \\ 2 Center for Advanced Studies in Olive Grove and Olive Oils, Science and Technology Park GEOLIT, \\ 23620 Mengíbar, Spain \\ 3 Departamento de Ingeniería Química, Facultad de Química, Universidad de Sevilla, \\ C/Profesor García González, 1, 41012 Seville, Spain \\ 4 Department of Chemical Engineering, Campus 'Fuente Nueva', University of Granada, 18071 Granada, Spain; \\ vbravo@ugr.es \\ * Correspondence: mcuevas@ujaen.es (M.C.); jfgarmar@us.es (J.F.G.M.)
}

Citation: Cuevas, M.; García Martín, J.F.; Bravo, V.; Sánchez, S.

Ethanol Production from Olive Stones through Liquid Hot Water

Pre-Treatment, Enzymatic Hydrolysis and Fermentation. Influence of

Enzyme Loading, and Pre-Treatment Temperature and Time. Fermentation 2021, 7, 25. https://doi.org/10.3390/ fermentation7010025

Received: 24 January 2021

Accepted: 14 February 2021

Published: 17 February 2021

Publisher's Note: MDPI stays neutral with regard to jurisdictional claims in published maps and institutional affiliations.

Copyright: () 2021 by the authors. Licensee MDPI, Basel, Switzerland. This article is an open access article distributed under the terms and conditions of the Creative Commons Attribution (CC BY) license (https:// creativecommons.org/licenses/by/ $4.0 /)$.

\begin{abstract}
Olive table industry, olive mills and olive pomace oil extraction industries annually generate huge amounts of olive stones. One of their potential applications is the production of bioethanol by fractionation of their lignocellulose constituents and subsequent fermentation of the released sugars using yeasts. In this work, we studied the influence of temperature $\left(175-225^{\circ} \mathrm{C}\right)$ and residence time (0-5 $\mathrm{min})$ in the liquid hot-water pre-treatment of olive stones as well as the initial enzyme loading (different mixtures of cellulases, hemicellulases and $\beta$-glucosidases) in the later enzymatic hydrolysis on the release of fermentable sugars. The Chrastil's model was applied to the D-glucose data to relate the severity of pre-treatment to enzyme diffusion through the pre-treated cellulose. Finally, the hydrolysate obtained under the most suitable conditions $\left(225^{\circ} \mathrm{C}\right.$ and $0 \mathrm{~min}$ for pre-treatment; 24 CE initial enzyme concentration) was fermented into ethanol using the yeast Pachysolen tannophilus ATCC 32691. Considering the overall process, $6.4 \mathrm{dm}^{3}$ ethanol per $100 \mathrm{~kg}$ olive stones were produced.
\end{abstract}

Keywords: autohydrolysis; bioethanol; Chrastil's model; enzymatic hydrolysis; olive stones; Pachysolen tannophilus

\section{Introduction}

Olive stones are a lignocellulose biomass that represent around 20\% of the olive weight [1]. Olive stones are largely generated not only in the olive table industry, but also in olive oil and olive pomace oil extraction industries after removing the olive stones from the olive pulp to extract olive oil or olive pomace oil, respectively [2]. The table olive industry is responsible for the generation of ca 30,000 $\mathrm{t}$ olives stones per year in Andalusia, the main worldwide producer region of table olives [3]. Meanwhile, and taking into account that olive stones account for approximately the same weight as the olive oil extracted from the fruit, and that $1.125 \times 10^{6} \mathrm{t}$ olive oil were obtained in the Spanish olive oil mills in the 2019/2020 campaign [4], these facilities would annually process around one million tons of olive stones.

As a lignocellulose material, the main components of olive stones are cellulose, hemicellulose and lignin. Because of this, one of the most promising energetic valorisation alternatives is the production of bioethanol. The production of ethanol from lignocellulose biomass via biochemical pathways has been the subject of numerous studies in recent decades. Most of the proposed schemes are composed of three main stages: pre-treatment 
of the biomass, enzymatic or acid hydrolysis of the pre-treated biomass and fermentation of the released sugars [2].

With regard to the pre-treatment stage, dilute acid hydrolysis at high temperatures [5-8], autohydrolysis or liquid hot water (LHW) pre-treatment [8-11] and steam explosion $[1,12,13]$ are the most common used biomass pre-treatments. LHW is of great interest because, unlike acid hydrolysis, it uses water as the only reagent in a facility that is easier to operate and maintain than steam explosion. When water is heated above $120^{\circ} \mathrm{C}$, ionization processes are promoted so that the $\mathrm{H}_{3} \mathrm{O}^{+}$concentration increases [14]. These ions, along with acetic acid and uronic acids released from hemicellulose by these ions' action, are responsible for the hemicellulose hydrolysis and partial cellulose (mainly amorphous cellulose) degradation $[14,15]$. The LHW pre-treatment can solubilize most of the hemicelluloses and extracts of olive stones, making pre-treated cellulose more accessible to enzyme attack in the subsequent hydrolysis stage. If the LHW process is carried out in a non-isothermal way, the treatment severity factor $\left(\log R_{0}\right)$ proposed by Overend and Chornet [16], which takes into account the combined effect of temperature and process time, could be applied.

The enzymatic hydrolysis with cellulolytic enzymes allows a selective conversion of cellulose into D-glucose under milder operating conditions ( $\mathrm{pH} 4.8,50^{\circ} \mathrm{C}$ temperature) and with a lower generation of fermentation inhibitors than acid hydrolysis. Notwithstanding, the use of enzymes is complex due to their high cost, polysaccharide selectivity of each type of enzyme and the different inhibitions that they can undergo in their hydrolytic actions $[17,18]$. Therefore, it is of great importance to assess the effect of enzyme type and enzyme loading to achieve high D-glucose yields at a relatively low enzyme cost.

To describe the behaviour of enzymes when acting on porous solids, the model proposed by Chrastil [19] can sometimes be used, which can describe the production of D-glucose, taking into account the diffusion of the enzymes within the solid (Equation (1)).

$$
P=P_{\infty} \cdot\left[1-\exp \left(-k_{E} \cdot C_{E 0} \cdot t\right)\right]^{n}
$$

The previous expression links the concentrations of products, which diffuse from the interior of the solid substrate at any time $(P)$ and at equilibrium $\left(P_{\infty}\right)$, with the initial concentration of enzymes $\left(C_{E 0}\right)$, the reaction time $(t)$, a specific rate constant $\left(k_{E}\right)$ that is proportional to the diffusion coefficient, and a factor of structural resistance to diffusion (n). When the resistance to diffusion of the biocatalyst through the solid is small, the parameter $n$ is close to 1 , while when the catalytic action is strongly limited by diffusion, $n$ has lower values, even lower than 0.5 . The Chrastil's model was applied to compare the enzymatic hydrolysis of native cellulose present in wheat straw and that resulting from the pre-treatment of the biomass with $\mathrm{NaOH}$. The alkaline pre-treatment raised the value of $n$ from 0.33 to 0.47 , which indicates a better accessibility of the enzymes to the substrate [20].

It is evident that the severity of LHW pre-treatment applied to biomass modifies the ease with which the cellulolytic enzymes act on the pre-treated cellulose. For this reason, it would be expected to find a relationship between the factors $\log R_{0}$ and $n$, a relationship that has not been studied previously, and therefore is not available in the literature.

In relation to the fermentation of sugars generated during the LHW pre-treatment and enzymatic hydrolysis stages, the use of non-traditional yeasts, such as Pachysolen tannophilus, would allow fermenting not only hexoses (such as D-glucose) but also pentoses (such as D-xylose) present in the culture $[6,7,9,21]$. The determination of certain kinetic parameters over fermentation, such as the maximum specific rates of growth, substrate uptake and bioproducts production, as well as the determination of the yields of biomass and bioproducts, could broaden the available information in the literature on the ability of $P$. tannophilus to produce ethanol from olive stones.

In the present work, LHW pre-treatments under different severity factors $\left(\log R_{0}\right)$ were applied to olive stones in order to modify their structure and make them accessible to enzymes. Subsequently, the enzymatic hydrolysis of the pre-treated cellulose was carried out and the characteristic parameters of Chrastil's equation $\left(k_{E}\right.$ and $\left.n\right)$ were determined. The aim was to achieve a relationship between $\log R_{0}$ and $n$. Finally, the fermentation of 
enzymatic hydrolysates using the yeast $P$. tannophilus was performed to assess the feasibility of the proposed scheme for the production of bioethanol from olive stones.

\section{Materials and Methods}

\subsection{Raw Material}

Olive stones (fragmented and moist endocarps) used throughout this research were supplied by an olive oil mill (S.C.A. San Juan, Spain, UTM coordinates: $37^{\circ} 47^{\prime} 58.52^{\prime \prime} \mathrm{N}$, $3^{\circ} 47^{\prime} 09.42^{\prime \prime} \mathrm{W}$ ). Once at the laboratory, olive stones were dried at room temperature until reaching equilibrium moisture (roughly $8 \%$ ). Afterwards, the olive stones went through a Vibro blade mill and sieve system (Retsch $\mathrm{GmbH}$, Haan, Germany) to reduce the particle size. The selected particle size selected for this research was that comprised between 0.300 and $0.425 \mathrm{~mm}$.

\subsection{Liquid Hot Water (LHW) Pre-Treatment}

The parameters selected to assess the LHW pre-treatment were the maximum pretreatment temperature $\left(T_{\text {pret }},{ }^{\circ} \mathrm{C}\right)$ and the maintenance time $\left(t_{\text {pret }}, \min \right)$ at $T_{\text {pret }}$. To do this, two sets of experiments were performed. In the first one, $T_{\text {pret }}$ varied from 175 to $225^{\circ} \mathrm{C}$, using $0 \mathrm{~min}$ as $t_{\text {pret }}$ at the given $T_{\text {pret }}$. In the second one, $T_{\text {pret }}$ was fixed to $220{ }^{\circ} \mathrm{C}$ and maintenance times of 1,2 and 5 minutes were assayed.

In order to perform the LHW pre-treatments, olive stones, once dried and with the selected particle size, were subjected to LHW pre-treatment in a 2- $\mathrm{dm}^{3}$ Parr batch reactor Series 4522 (Moline, IL, USA). Fifty grams of olive stones, along with $300 \mathrm{dm}^{3}$ distilled water, were loaded inside the reactor, which was then hermetically closed. Once the equipment was closed, the stirring system was set to $250 \mathrm{rpm}$ and the reactor heating-cooling system began to act, achieving three different stages in the biomass pre-treatment: a) the heating stage, which lasts until the mixture reaches $T_{\text {pret }} ; b$ ) the maintenance stage, in which $T_{\text {pret }}$ is maintained for a selected $t_{\text {pret }}$ c) the cooling stage, in which the temperature of the system is rapidly reduced from $T_{\text {pret }}$ to temperatures below $100{ }^{\circ} \mathrm{C}$. From the evolution of temperatures over pre-treatment (Figure 1$)$, the parameter $\left(\log R_{0}\right)$, indicator of the severity of the pre-treatment could be calculated using the procedure described in previous articles $[9,22]$. Once the system was cooled down, the Parr reactor was opened, and its content (pre-treated liquid and solid phases) was made up to $200 \mathrm{dm}^{3}$ with distilled water and then transferred to a jacketed reactor for enzymatic hydrolysis.

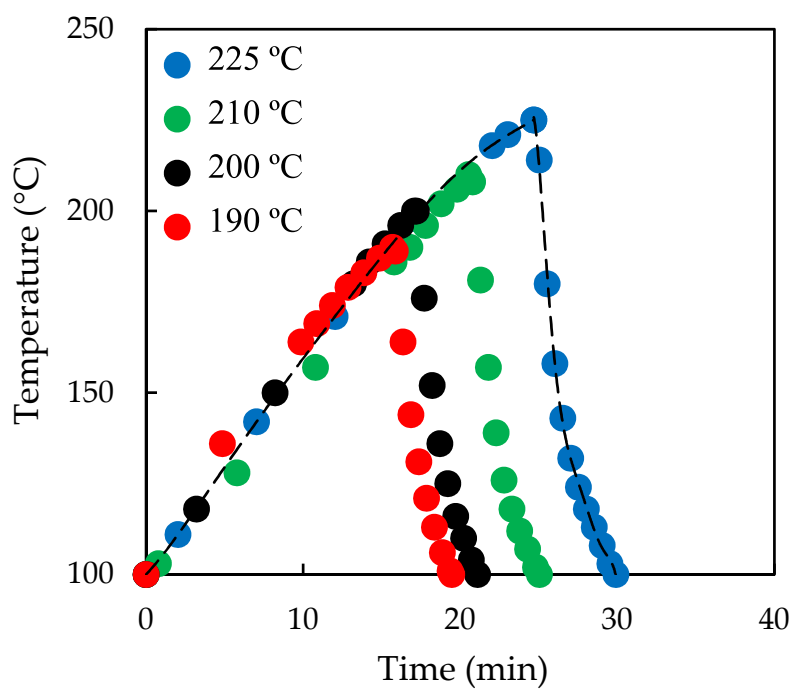

Figure 1. Temperature profiles for LHW pre-treatments performed at four different maximum temperatures and $0 \mathrm{~min}$ maintenance time at these temperatures. 


\subsection{Enzymatic Hydrolysis}

Three commercial enzymes supplied by Sigma Chemical Co. (St. Louis, MO), namely cellulases (EC 3.2.1.4. from Trichoderma viride), $\beta$-glucosidases (EC 3.2.1.21. from almonds) and hemicellulases (from Aspergillus niger), were used for the enzymatic hydrolysis of the pre-treated olive stones. The enzymatic hydrolyses were carried out at $45^{\circ} \mathrm{C}$ and $\mathrm{pH} 5.0$ in a 1-dm ${ }^{3}$ Pyrex-glass jacketed reactor. A Teflon anchor rod driven by a RZR-2000 stirrer (Heidolph, Schwabach, Germany) was used to set a stirring of $250 \mathrm{rpm}$.

Table 1 shows the enzymatic loadings used in the different enzymatic hydrolyses, so that the figures refer to a reference value of enzymatic activity equal to $345 \mathrm{IU}$. Thus, for example, an amount of cellulases equivalent to a cellulase activity of $6 \times 345=2070 \mathrm{IU}$ was used for enzymatic hydrolysis EL-1, along with an amount of $\beta$-glucosidases equivalent to a $\beta$-glucosidase activity of $1 \times 345=345$ UI. Samples were withdrawn from the reactor at fixed time intervals to assess the evolution of hydrolysis over time by determining the content of D-glucose. Once the enzymatic hydrolysis was finished, the liquid and solid phases were separated by filtration. The former was stored at a low temperature $\left(-18^{\circ} \mathrm{C}\right)$ until subsequent fermentation experiments. Regarding the solid, it was washed with distilled water and dried prior to proceeding with its characterization.

Table 1. Relative enzymatic activities * assayed for enzymatic hydrolysis.

\begin{tabular}{cccc}
\hline \multirow{2}{*}{ Enzyme Loading } & \multicolumn{3}{c}{ Relative Enzymatic Activity } \\
\cline { 2 - 4 } & Cellulases & B-Glucosidases & Hemicellulases \\
\hline EL-1 & 6 & 1 & 0 \\
EL-2 & 8 & 1 & 0 \\
EL-3 & 12 & 1 & 0 \\
EL-4 & 24 & 1 & 0 \\
EL-5 & 12 & 0 & 0 \\
EL-6 & 24 & 0 & 0 \\
EL-7 & 12 & 1 & 1 \\
\hline
\end{tabular}

* A relative enzymatic activity of 1 stands for 345 UI enzymatic activity.

\subsection{Fermentation of Enzymatic Hydrolysates}

The non-traditional yeast Pachysolen tannophilus ATCC 32691 (from the American Type Culture Collection) was used to ferment the enzymatic hydrolysates under microaerobic conditions at $30^{\circ} \mathrm{C}$ and $\mathrm{pH} 4.5$. The overall volumetric mass-transfer coefficient at the beginning of the fermentations was $2.9 \mathrm{~h}^{-1}$. A comprehensive description of the procedure can be found elsewhere [9].

\subsection{Analytical Methods}

The solid biomasses (raw material, pre-treated solids and solids resulting from enzymatic hydrolyses) were characterized according to their contents in moisture (TAPPI T11 m-59 standard), Acid Insoluble Lignin (AIL; TAPPI T222 os-74 standard), Neutral Detergent Fibre (NDF) and Acid Detergent Fibre (ADF). The percentages of hemicellulose (HEM) and cellulose (CEL) in the different solids were calculated from the values of AIL, NDF and $A D F$ by applying Equations (2) and (3)

$$
\begin{gathered}
\operatorname{HEM}(\%)=\operatorname{NDF}(\%)-A D F(\%) \\
C E L(\%)=A D F(\%)-A I L(\%)
\end{gathered}
$$

The concentration of D-glucose $(g)$ in the enzymatic hydrolysates and in the fermentation cultures, as well as the concentrations of acetic acid $(A A)$, ethanol $(E)$ and xylitol $(X y)$ in the fermentation media, were calculated by enzymatic methods of Trinder [23], Bergmeyer and Möllering [24], Beutler [25] and Beutler and Becker [26], respectively. For the determination of total reducing sugars (TRS) in the fermentation stage, the dinitrosalicylic acid colorimetric method was used. The cell concentration of $P$. tannophilus $(x)$ was calculated 
from a calibration line that relates the dry weight of biomass with the absorbance of the cell suspension [27]. All the analytical determinations were performed in duplicate.

\section{Results and Discussion}

The raw material used in this work contained a low percentage of cellulose $(25.3 \%)$ along with a high percentage of acid-insoluble lignin (33.5\%), which could hindrance the production of D-glucose via enzymatic hydrolysis. On the other hand, hemicellulose stood for $33.9 \%$ dry weight of olive stones.

\subsection{Effect of Pre-Treatment Temperature on Subsequent Enzymatic Hydrolysis}

Five LHW pre-treatments were performed on olive stones at 175, 190, 200, 210 and $225^{\circ} \mathrm{C}$, respectively, with $t_{\text {pret }}=0 \mathrm{~min}$, equivalent to applying $\log R_{0}$ values between 2.73 and 4.39. Table 2 shows, for each LHW pre-treatment, the $\log R_{0}$ values as well as the fibre composition (cellulose, hemicellulose and acid-insoluble lignin) of the pre-treated solids. As can be observed in this Table, the increase in the severity of pre-treatment resulted in a continuous decrease in the percentage of hemicellulose while, in general, the percentages of cellulose and insoluble acid lignin increased.

Table 2. Effect of liquid hot-water (LHW) pre-treatment temperature ( $\left.T_{\text {pret }}\right)$ on the composition of pre-treated solids.

\begin{tabular}{cccccccc}
\hline & & \multicolumn{5}{c}{$\begin{array}{c}\text { Pre-Treated Solids' } \\
\text { Composition }\end{array}$} \\
\hline $\begin{array}{c}\text { LHW } \\
\text { Pre-Treatment }\end{array}$ & $\begin{array}{c}\boldsymbol{T}_{\text {pret }} \\
\left({ }^{\circ} \mathbf{C}\right)\end{array}$ & $\begin{array}{c}\boldsymbol{t}_{\text {pret }} \\
(\mathbf{m i n})\end{array}$ & $\log \boldsymbol{R}_{\mathbf{0}}$ & $\begin{array}{c}C E L \\
(\%)\end{array}$ & $\begin{array}{c}\text { HEM } \\
(\%)\end{array}$ & $\begin{array}{c}A I L \\
(\%)\end{array}$ & $\begin{array}{c}\text { Enzymatic } \\
\text { Hydrolysis }\end{array}$ \\
\hline P175-0 & 175 & 0 & 2.73 & 26.5 & 35.4 & 34.7 & EH175-0 \\
P190-0 & 190 & 0 & 3.23 & 27.1 & 19.8 & 43.7 & EH190-0 \\
P200-0 & 200 & 0 & 3.46 & 24.1 & 26.0 & 39.6 & EH200-0 \\
P210-0 & 210 & 0 & 3.79 & 29.8 & 6.8 & 45.5 & EH210-0 \\
P225-0 & 225 & 0 & 4.39 & 38.2 & 0.0 & 42.3 & EH225-0 \\
\hline
\end{tabular}

tpret: pre-treatment time; CEL: cellulose; HEM: hemicellulose; AIL: acid-insoluble lignin.

The slurries from the previous five pre-treatments (P175-0 to P225-0 LHW pre-treatments) were enzymatically hydrolysed (EH175-0 to EH225-0 enzymatic hydrolyses) with cellulases using 2070 IU enzyme loading (EL-5 in Table 1). The analysis of the solids obtained after the action of the enzymes (data not shown) revealed a low hydrolytic capacity of cellulases, except when it was applied to the solid obtained from P225-0. In this case, enzymatic hydrolysis led to a solid with $8.7 \%$ cellulose, a significantly lower percentage than the starting cellulose content $(38.2 \%)$. From the previous values, the mass balance to the solids before and after the enzymatic hydrolysis EH225-0 resulted in $82.8 \%$ pre-treated cellulose removal. Similar values of enzymatic digestibility have been reported from ammonia-pre-treated corn stover [28] and from steam-exploded barley straw [29].

With regard to the evolution of the D-glucose concentration in the liquid hydrolysates over enzymatic hydrolysis, the pre-treatment at $225^{\circ} \mathrm{C}$ was the most effective for sugar production (Figure 2).

The generation of D-glucose over enzymatic hydrolysis could be studied by applying the Chrastil's model. To do this, Equation (1) became the following expression

$$
k_{E}=-\frac{\operatorname{Ln}\left[1-\left(\frac{g}{g_{f}}\right)^{\frac{1}{n}}\right]}{C_{E 0} \cdot t}
$$

where $g$ and $g_{\mathrm{f}}$ stand for D-glucose concentration at a given time $t$ and at equilibrium, respectively. 


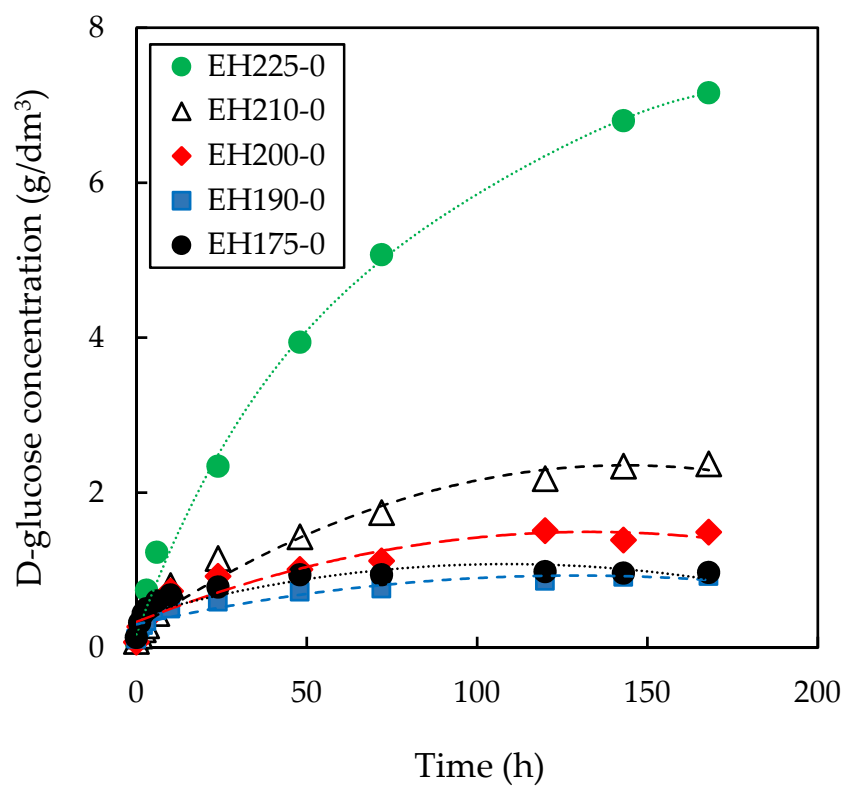

Figure 2. Evolution of the D-glucose concentration in the enzymatic hydrolyses carried out on the pre-treated slurries obtained at different temperatures $\left(175-225^{\circ} \mathrm{C}\right)$.

By representing the numerator of Equation (4) against the denominator, a straight line of slope $k_{E}$ and a y-intercept of zero were obtained. Using an iterative calculation method, using the Microsoft Excel software, the value of the parameter $n$ was determined, for which the best fit of the straight line was obtained. Table 3 shows the $k_{E}$ and $n$ values obtained by applying the Chrastil model. It is observed that the parameter $n$ was very low for the three pre-treatments carried out at the lowest temperatures $\left(175,190\right.$ and $\left.200^{\circ} \mathrm{C}\right)$, which illustrates how the physical transport stages of the enzymes through the solid would limit the overall D-glucose generation rate. Notwithstanding, $n$ values of 0.60 and 1.00 were obtained for solids pre-treated at 210 and $225^{\circ} \mathrm{C}$, respectively.

Table 3. Effects of LHW pre-treatment temperature on Chrastil's model parameters.

\begin{tabular}{|c|c|c|c|c|}
\hline Enzymatic Hydrolysis & $C_{E 0}\left(\mathrm{~g} / \mathrm{dm}^{3}\right)$ & $k_{E} 10^{3}\left(\mathrm{dm}^{3} / \mathrm{g} \cdot \mathrm{min}\right)$ & $n$ & $r^{2}$ \\
\hline EH175-0 & 1.08 & 0.33 & 0.22 & 0.978 \\
\hline EH190-0 & 1.08 & 0.20 & 0.29 & 0.995 \\
\hline EH200-0 & 1.08 & 0.08 & 0.25 & 0.993 \\
\hline EH210-0 & 1.09 & 0.20 & 0.60 & 0.995 \\
\hline $\mathrm{EH} 225-0$ & 1.08 & 0.29 & 1.00 & 0.994 \\
\hline
\end{tabular}

\subsection{Effect of Pre-Treatment Maintenance Time on Subsequent Enzymatic Hydrolysis}

To study the effect of $t_{\text {pret }}$ of LHW pre-treatment on the enzymatic hydrolysis, three tests were performed in which olive stones were pre-treated at $200{ }^{\circ} \mathrm{C}$ for 1,2 and $5 \mathrm{~min}$, equivalent to applying $\log R_{0}$ values between 3.60 and 3.90. Table 4 shows the $\log R_{0}$ value as well as the fibre composition (cellulose, hemicellulose and acid-insoluble lignin) of the pre-treated solids for each pre-treatment. Similar to what was found with the increase in $T_{\text {pret}}$, there was a strong decrease in the percentage of hemicellulose in the pre-treated solids (from $19.5 \%$ to $0 \%$ ) as $t_{\text {pret }}$ increased, which led to mild increases in the percentages of cellulose and acid-insoluble lignin. The slurries resulting from the LWT pre-treatments were enzymatically hydrolysed with $2070 \mathrm{IU}$ cellulase loading (Table 4). The enzymatic hydrolysis of the slurry obtained with the highest $t_{\text {pret }}$ (EH200-5) resulted in a solid containing $23.4 \%, 1.6 \%$ and $50.1 \%$ cellulose, hemicellulose and AIL, respectively. 
Table 4. Effect of LHW pre-treatment time $\left(t_{\text {pret }}\right)$ on pre-treated solids.

\begin{tabular}{cccccccc}
\hline & \multicolumn{7}{c}{ Solid Composition } \\
\hline $\begin{array}{c}\text { LHW } \\
\text { Pre-Treatment }\end{array}$ & $\boldsymbol{T}_{\text {pret }}\left({ }^{\circ} \mathbf{C}\right)$ & $\begin{array}{c}\boldsymbol{t}_{\text {pret }} \\
(\mathbf{m i n})\end{array}$ & Log $\boldsymbol{R}_{\mathbf{0}}$ & CEL (\%) & HEM (\%) & AIL (\%) & $\begin{array}{c}\text { Enzymatic } \\
\text { Hydrolysis }\end{array}$ \\
\hline P200-1 & 200 & 1 & 3.60 & 28.7 & 19.5 & 39.9 & EH200-1 \\
P200-2 & 200 & 2 & 3.67 & 32.2 & 13.8 & 40.7 & EH200-2 \\
P200-5 & 200 & 5 & 3.90 & 34.4 & 0.0 & 40.2 & EH200-5 \\
\hline
\end{tabular}

$T_{\text {pret }}$ : pre-treatment temperature; CEL: cellulose; HEM: hemicellulose; AIL: acid-insoluble lignin.

The increase of the pre-treatment time from 1 to $5 \mathrm{~min}$ led to an increase in the concentration of D-glucose released in the enzymatic hydrolysis step. Thus, the final concentrations of D-glucose were $2.18 \mathrm{~g}$ and $2.84 \mathrm{~g} / \mathrm{dm}^{3}$ for EH200- 1 and EH200-5, respectively. The parameters calculated by applying the Chrastil's model to the experimental data of this set of experiments are shown in Table 5.

Table 5. Effects of LHW pre-treatment time on Chrastil's model parameters.

\begin{tabular}{ccccc}
\hline Enzymatic Hydrolysis & $C_{E \mathbf{0}}\left(\mathrm{g} / \mathbf{d m}^{\mathbf{3}}\right)$ & $\left.\boldsymbol{k}_{E} \mathbf{1 0}^{\mathbf{3}} \mathbf{( \mathbf { d m }} \mathbf{3} \cdot \mathbf{g} \mathbf{m i n}\right)$ & $n$ & $\boldsymbol{r}^{\mathbf{2}}$ \\
\hline EH200-1 & 1.07 & 0.22 & 0.43 & 0.991 \\
EH200-2 & 1.07 & 0.41 & 0.66 & 0.997 \\
EH200-5 & 1.08 & 0.16 & 0.38 & 0.995 \\
\hline
\end{tabular}

With the values of $n$ calculated both by modifying the temperature and the pretreatment time, it is possible to assess the evolution of said parameter as a function of $\log R_{0}$. It was found that the higher the severity of the LHW pre-treatment ( $\log R_{0}$ from 2.73 to 4.39 ), the higher the $n$ value (from 0.22 to 1.00) (Figure 3). In a study on the use of the Chrastil's model in the enzymatic hydrolysis of sugarcane bagasse pre-treated by different methods [30], $n$ values between 0.3 (acid pre-treatment) and 0.85 (steam explosion pre-treatment) were achieved, which are in the range of those found for LHW pre-treatment in this research. For the latter pre-treatment (steam explosion), a $k_{E}$ value of $0.2 \times 10^{-3}$ was also obtained in the subsequent enzymatic hydrolysis, a value very close to that determined in the present study for EH210-0 (Table 3) and EH200-1 (Table 5). Therefore, it can be concluded that the most suitable LHW pre-treatment of olive stones for subsequent enzymatic hydrolysis was the one carried out at $225^{\circ} \mathrm{C}$ for $t_{\text {pret }}=0$.

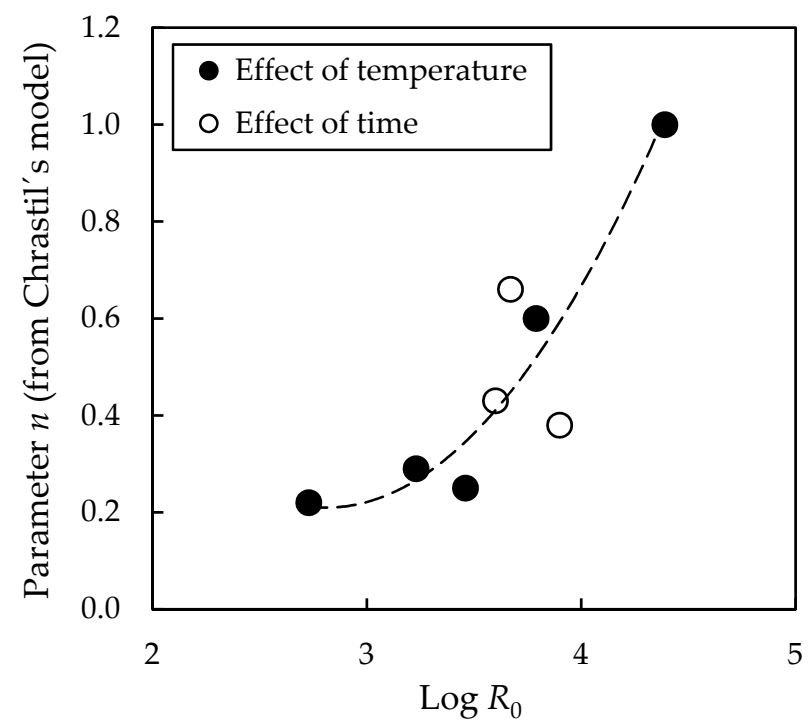

Figure 3. Effect of LHW pre-treatment severity parameter $\left(\log R_{0}\right)$ on the parameter $n$ of the Chrastil's model. 


\subsection{Effect of Initial Enzyme Concentration on Enzymatic Hydrolysis of Pre-Treated Slurries}

Once the effect of the LHW pre-treatment severity on the enzymatic digestibility of pretreated cellulose was studied, a new set of experiments was performed, aiming to determine the effect of the addition of different loadings and types of enzyme (cellulases, $\beta$-glucosidase and hemicellulases) on the slurry pretreated at $225^{\circ} \mathrm{C}$ for $t_{\text {pret }}=0$.

The mean value and the standard deviation of $\log R_{0}$ for the seven LWH pretreatments carried out in this set of experiments were 4.27 and 0.08 , respectively. The enzymatic loadings used were those illustrated in Table 1 (from EL-1 to EL-7), while the D-glucose yields achieved and composition of the resulting solids from the enzymatic hydrolysis step are shown in Table 6. The percentage of hemicellulose in these solids is not shown because it was zero after all the LWH pre-treatments. Data collected from the first four experiments (from EL-1 to EL-4) showed that the increase in the cellulase loading (keeping the $\beta$-glucosidase loading constant) was responsible for a continuous increase, from 0.015 to $0.056 \mathrm{~kg} / \mathrm{kg}$, in D-glucose yield after $144 \mathrm{~h}$ of bioprocess, as a consequence of the hydrolysis of the cellulose fraction. As a result, the percentage of cellulose in the pretreated solid decreased, as a consequence of the enzymatic hydrolysis, from $28.5 \%$ to $8.0 \%$ and that of AIL increased from $50.8 \%$ to $61.4 \%$. However, when comparing the results of EL-3 with those of EL-4, it was detected that a $100 \%$ increase in the cellulases loading barely increased the D-glucose yield (from 0.055 to $0.056 \mathrm{~kg} / \mathrm{kg}$ ). A similar impact was observed between EL-5 and EL-6, where a 100\% increase in cellulase loading (without the presence of $\beta$-glucosidases) caused an increase of $10.1 \%$ in the D-glucose yield. On the other hand, Table 6 illustrates that the enzymatic hydrolysis carried out in the presence of cellulases, $\beta$-glucosidases and hemicellulases (EL-7) as well as cellulases and $\beta$-glucosidases (EL-3), were less effective for the production of D-glucose than those performed solely with cellulases (EL-5). The cellulase inhibition provoked by $\beta$-glucosidases and hemicellulases could account for this fact.

Table 6. D-glucose yields $\left(Y_{G}\right)$ and composition of the resulting solids from the enzymatic hydrolyses performed with different enzyme loadings.

\begin{tabular}{cccc}
\hline Enzymatic Hydrolysis & $\begin{array}{c}\mathbf{Y}_{G} \cdot \mathbf{1 0}^{\mathbf{2}} \\
\mathbf{( k g / k g )}\end{array}$ & $\begin{array}{c}\text { CEL } \\
\mathbf{( \% )}\end{array}$ & $\begin{array}{c}\text { AIL } \\
\mathbf{( \% )}\end{array}$ \\
\hline EL-1 & 1.5 & 28.5 & 50.8 \\
EL-2 & 2.8 & 13.2 & 54.3 \\
EL-3 & 5.5 & 10.7 & 56.5 \\
EL-4 & 5.6 & 8.0 & 61.4 \\
EL-5 & 5.9 & 8.7 & 59.1 \\
EL-6 & 6.5 & 10.8 & 57.1 \\
EL-7 & 3.9 & 17.6 & 53.9 \\
\hline
\end{tabular}

$\overline{H E M}=0 \%$ for all the experiments. CEL: cellulose; AIL: acid-insoluble lignin; HEM: hemicellulose.

The release of D-glucose over $144 \mathrm{~h}$ for the enzymatic hydrolyses carried out with different enzyme loadings and types is depicted in Figure 4. Chrastil's model could be applied to these data in order to modelling the D-glucose production. The parameters $k_{E}$ and $n$ for the seven enzymatic hydrolyses performed are shown in Figure 5 as a function of the enzyme concentration. The increase in enzyme concentration was responsible for a decrease in both $k_{E}$ and $n$. The decrease in parameter $n$ with the increase in $C_{E 0}$ could be due to steric repulsions produced among the globular structures of the proteins inside the solid biomass [20]. 


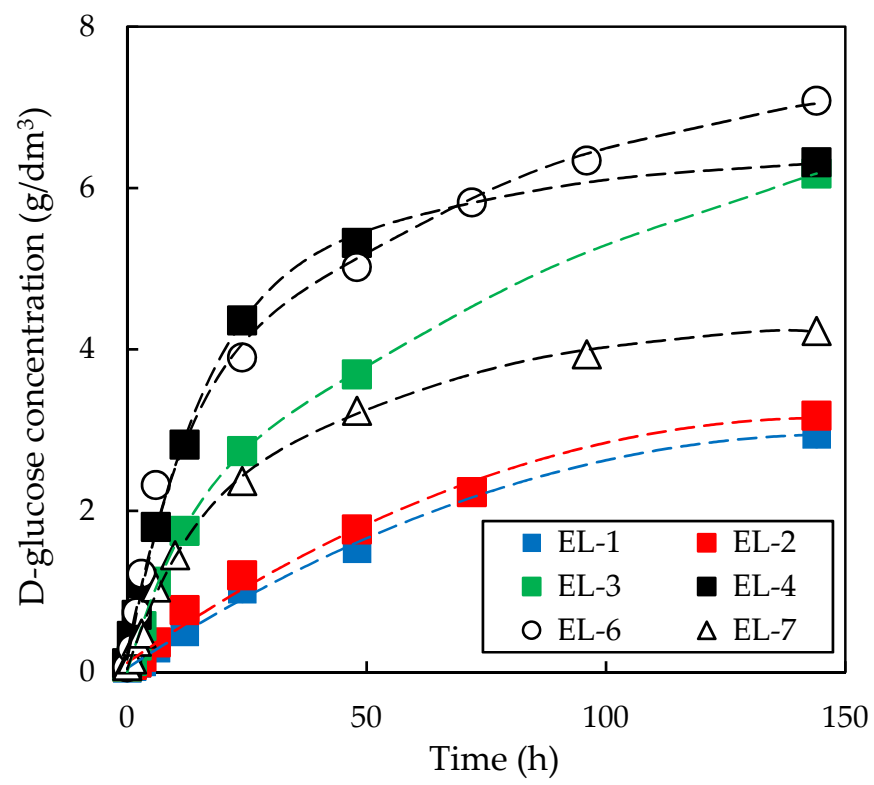

Figure 4. Evolution of D-glucose concentration over time for the enzymatic hydrolyses performed with different enzyme loadings.

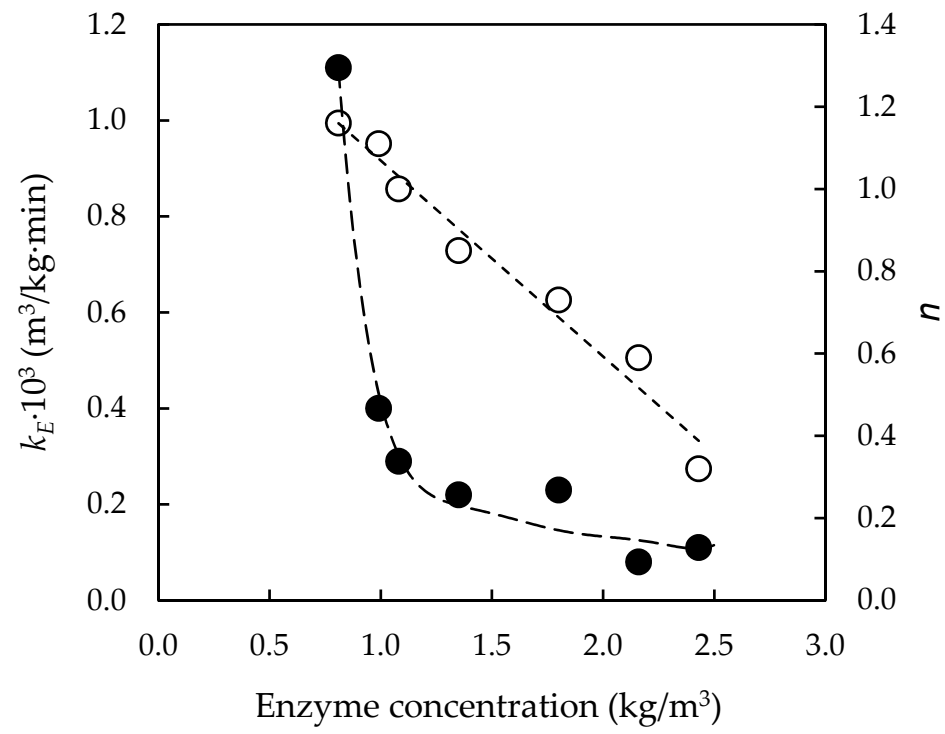

Figure 5. Effect of initial enzyme concentration on Chrastil's model parameters ( $k_{E}$, black circles; $n$, open circles).

\subsection{Fermentation of Enzymatic Hydrolysates with P. tannophilus}

The hydrolysate that achieved the highest D-glucose yield from enzymatic hydrolysis (EL-6, $Y_{G}=0.065 \mathrm{~kg} / \mathrm{kg}$ dry raw material) was subjected to fermentation with the nontraditional yeast $P$. tannophilus. The total reducing sugars' yield after enzymatic hydrolysis (D-glucose, D-xylose, L-arabinose, etc.) was $0.271 \mathrm{~kg}$ per $\mathrm{kg}$ dry raw material, of which $0.106 \mathrm{~kg} / \mathrm{kg}$ corresponded to sugars generated in the enzymatic hydrolysis, while the rest were sugars released in the LHW pre-treatment and which, therefore, were already in the slurry at the beginning of the enzymatic stage.

The evolution of the concentrations of total reducing sugars, D-glucose, acetic acid, ethanol, yeast biomass and xylitol over fermentation is illustrated in Figure 6. In relation to the analysed substrates, a rapid consumption of D-glucose was observed, so that D-glucose was barely detected after $48.5 \mathrm{~h}$. Of note is that TRS uptake within the first 
$31.5 \mathrm{~h}\left(2.31 \mathrm{~g} / \mathrm{dm}^{3}\right)$ was very close to the D-glucose uptake in that period $\left(2.01 \mathrm{~g} / \mathrm{dm}^{3}\right)$. By contrast, the rest of the sugars (included in the TRS measurement along with D-glucose) and acetic acid were assimilated more slowly by the yeast, and were not completely uptaken after $341.5 \mathrm{~h}$ of bioprocess. Other studies have already illustrated the ability of $P$. tannophilus to assimilate both D-xylose and acetic acid [6,9]. With regard to bioproducts, there was an increase in the concentrations of ethanol, biomass and xylitol over fermentation, although the ethanol began to be uptaken by the yeast after $246.5 \mathrm{~h}$, which resulted in a drastic reduction in cell growth.

By analysing the growth curve of P. tannophilus during fermentation in greater detail, it was possible to verify the existence of a diauxic-type cell development: i.e., in the first stage, up to $31.5 \mathrm{~h}$, the yeast develops through the almost exclusive uptake of D-glucose. The maximum specific growth rate in this phase $\left(\mu_{m}=0.036 \mathrm{~h}^{-1}\right)$ was obtained by fitting the experimental data to Equation (5)

$$
x=x_{0} \cdot \exp \left(\mu_{m} \cdot t\right)
$$

where $x_{0}$ stands for the initial biomass concentration and $t$ is the fermentation time (Figure 7). Subsequently, between 48.5 and $126.5 \mathrm{~h}$, the yeast adapted its metabolic system to the uptake of other substrates, which represented a second stage of slower cell growth and could be described by Equation (6)

$$
x=\mathrm{c}+\mathrm{b} \cdot t
$$

where $\mathrm{b}$ stands for the biomass productivity $\left(0.18 \times 10^{-2} \mathrm{~kg} /\left(\mathrm{m}^{3} \cdot \mathrm{h}\right)\right)$.

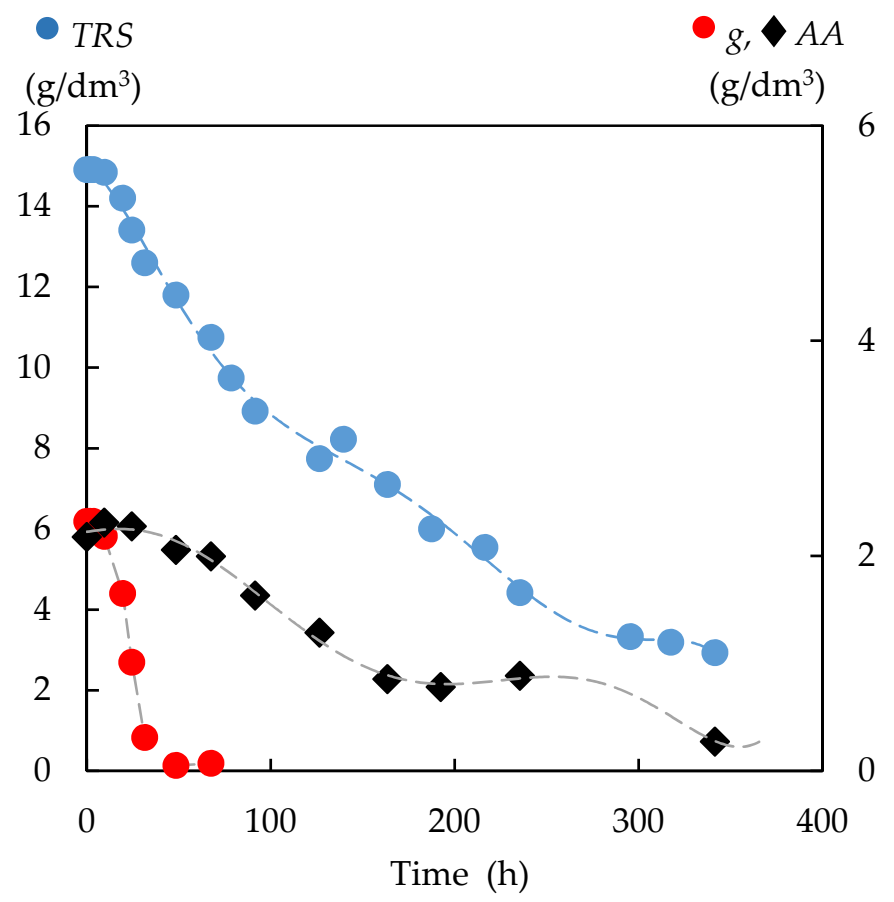

(A)

Figure 6. Cont. 


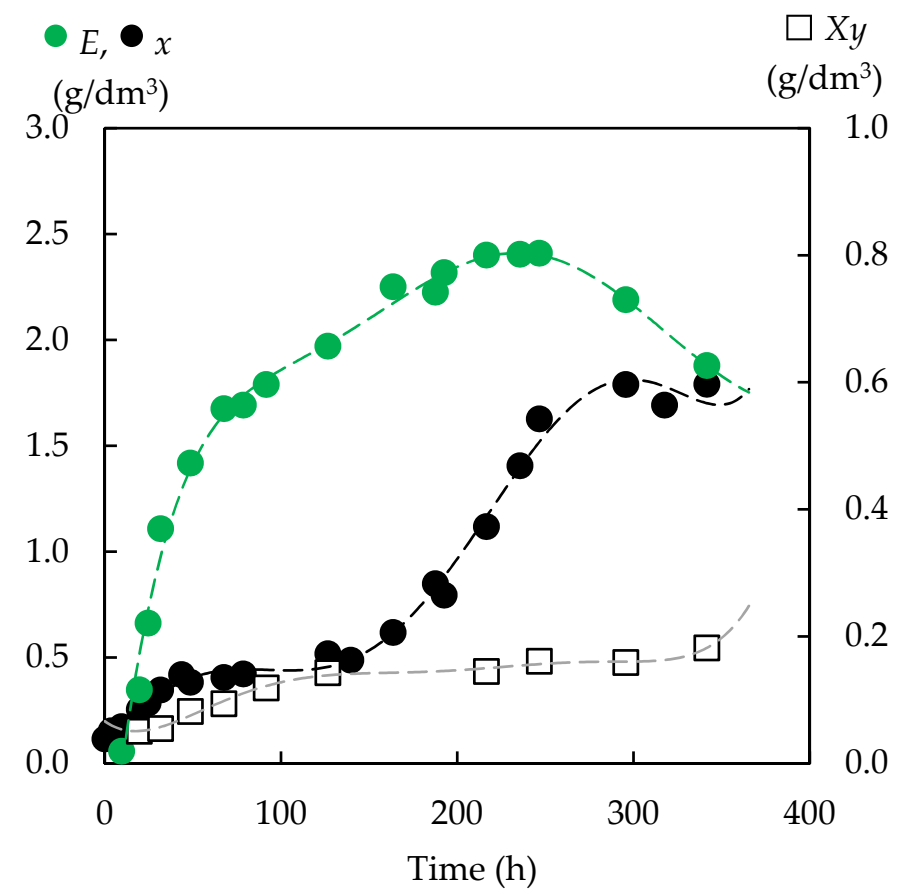

(B)

Figure 6. Fermentation with P. tannophilus of olive stones hydrolysates. Evolution over time of (A) substrates: total reducing sugars (TRS), D-glucose $(g)$ and acetic acid $(A A)$; and (B) bioproducts: ethanol $(E)$, biomass $(x)$ and xylitol $(X y)$.

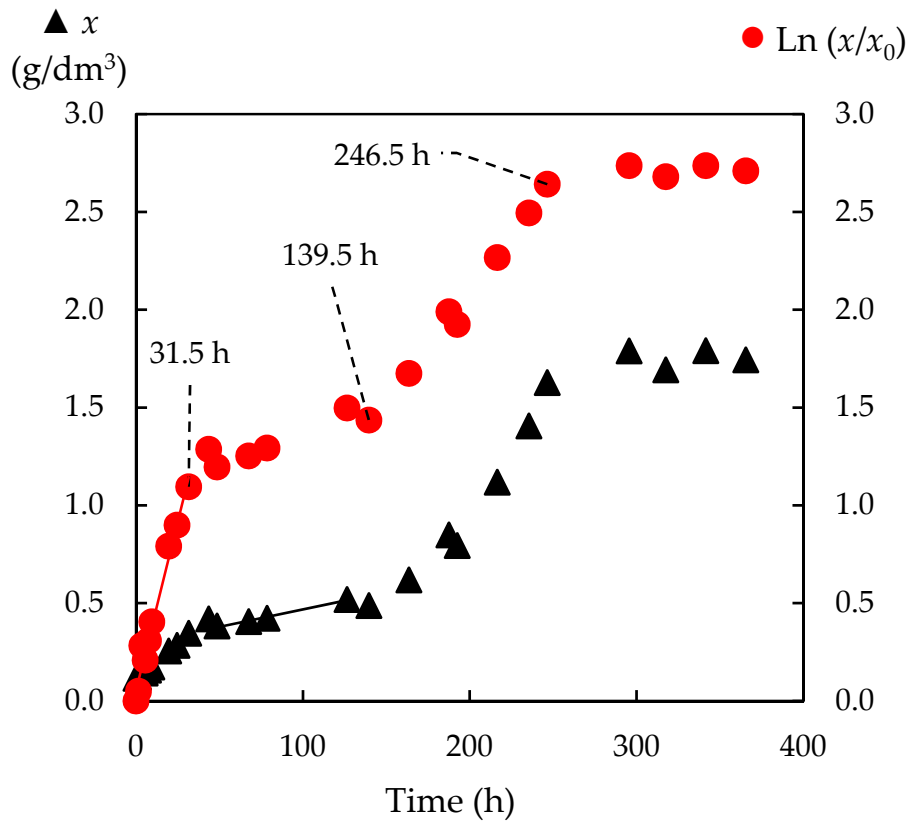

Figure 7. P. tannophilus growth curve under microaerobic conditions at $30^{\circ} \mathrm{C}$ and $\mathrm{pH} 4.5$.

\subsubsection{Kinetics of the Total Reducing Sugar Uptake}

The differential and integral methods for data treatment were used to assess the kinetics of substrate uptake, as described in previous works [31,32]. To determine the 
specific substrate uptake rate $\left(q_{s}\right)$, it was assumed that the concentration of a substrate $s$ changes over time, according to Equation (7).

$$
s=s_{0} \cdot \alpha^{-t^{\beta}}
$$

where $\mathrm{s}_{0}$ is the initial substrate concentration, $\mathrm{t}$ is a given time, and $\alpha$ and $\beta$ are parameters to experimentally determine. Equation (7) meets the requirement that $s=s_{0}$ for $t=0$.

From this equation, $q_{s}$ can be determined as a function of time. To determine the parameters $\alpha$ and $\beta$ in Equation (7), the expression can be linearized so that the parameters $\alpha$ and $\beta$ can be obtained from the representation of the first member against $(\ln t)$.

Two straight lines were obtained when plotting $\operatorname{Ln}\left(\operatorname{Ln}\left(T R S_{0} / T R S\right)\right)$ vs. $\operatorname{Ln} t$ (Figure 8A) in the assayed fermentation because of the sequential substrate uptake. As shown in Figure 8B, Equation (7) allowed for an accurate description of the evolution of TRS uptake over fermentation. The specific uptake rates of D-glucose and those of the rest of the total reducing sugars are illustrated in Table 7 . It can be observed that the highest specific D-glucose uptake rate $(0.403 \mathrm{~kg} / \mathrm{kg} \cdot \mathrm{h})$ was obtained at $20 \mathrm{~h}$, while the specific uptake rates of the rest of TRS ranged between 0.091 and $0.027 \mathrm{~kg} / \mathrm{kg} \cdot \mathrm{h}$.

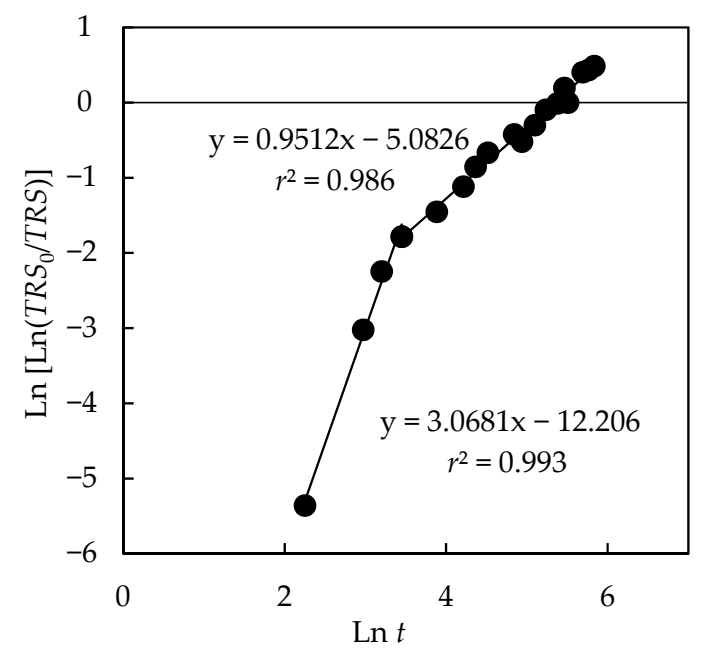

(A)

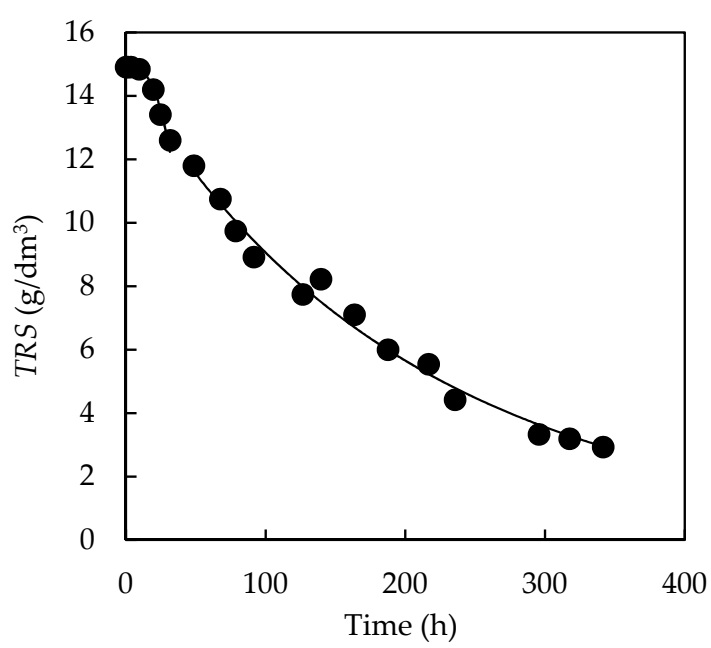

(B)

Figure 8. Total reducing sugar uptake over fermentation with $P$. tannophilus. (A) Fit of the experimental data to equation (5). (B) Comparison of the experimental concentrations (black points) with those predicted by model (line). 
Table 7. Specific substrate uptake and ethanol production rates.

\begin{tabular}{|c|c|c|c|c|c|c|c|}
\hline \multicolumn{5}{|c|}{ Substrates Uptake } & \multicolumn{3}{|c|}{ Ethanol Production } \\
\hline $\begin{array}{c}t \\
(\mathrm{~h})\end{array}$ & $\begin{array}{c}q_{g}^{D} \\
(\mathrm{~kg} / \mathrm{kg} \cdot \mathrm{h})\end{array}$ & $\begin{array}{c}q_{g} \\
(\mathrm{~kg} / \mathrm{kg} \cdot \mathrm{h})\end{array}$ & $\begin{array}{c}q_{s}^{D} \\
(\mathrm{~kg} / \mathrm{kg} \cdot \mathrm{h})\end{array}$ & $\begin{array}{c}q_{s} \\
(\mathrm{~kg} / \mathrm{kg} \cdot \mathrm{h})\end{array}$ & $\begin{array}{c}t \\
\text { (h) }\end{array}$ & $\begin{array}{c}q_{E}^{D} \\
(\mathrm{~kg} / \mathrm{kg} \cdot \mathrm{h})\end{array}$ & $\begin{array}{c}q_{E} \\
(\mathrm{~kg} / \mathrm{kg} \cdot \mathrm{h})\end{array}$ \\
\hline 10 & 0.237 & 0.319 & - & - & 10 & 0.100 & 0.254 \\
\hline 20 & 0.403 & 0.319 & - & - & 15 & 0.153 & 0.254 \\
\hline 100 & - & - & 0.091 & 0.090 & 25 & 0.218 & 0.254 \\
\hline 150 & - & - & 0.062 & 0.042 & 50 & 0.028 & 0.034 \\
\hline 200 & - & - & 0.027 & 0.042 & 75 & 0.019 & 0.013 \\
\hline
\end{tabular}

$q_{g}^{D}$ and $q_{g}$ : Specific D-glucose consumption rates determined by differential method and by integral method, respectively. $q_{s}^{D}$ and $q_{s}$ : Specific substrate (different to D-glucose) consumption rates determined by differential method and by integral method, respectively. $q_{E}^{D}$ and $q_{E}$ : Specific ethanol production rates determined by differential method and by integral method, respectively.

\subsubsection{Biomass Yield}

The biomass yield parameter expresses the amount of uptaken substrate that is transformed into biomass. Conditions should be sought that simultaneously promote low biomass yields and high bioproduct yields. The global biomass yields in fermentation were calculated, representing the concentration of biomass produced against the concentration of uptaken substrates (Figure 9). In the studied bioprocess, it was possible to calculate global biomass yield values referring to the uptake of total reducing sugars $\left(Y_{x / T R S}^{G}\right)$ and to the consumption of both total reducing sugars and acetic acid $\left(Y_{x /(T R S+A A)}^{G}\right)$. As seen in Figure 9, two practically coincident lines were obtained at low values of $\left(x-x_{0}\right)$ for both the aforementioned biomass yields, which allowed for the determination of a biomass yield referring to the uptake of D-glucose $(0.11 \mathrm{~kg}$ biomass $/ \mathrm{kg}$ D-glucose). After the consumption of hexose, two straight lines, practically parallel, were achieved, from which the values of $Y_{x / T R S}^{G}=0.27 \mathrm{~kg} / \mathrm{kg}$ and of $Y_{x /(T R S+A A)}^{G}=0.25 \mathrm{~kg} / \mathrm{kg}$ were calculated (Figure 9). The biomass yields calculated in the D-glucose uptake phase were considerably lower than those determined during the uptake of the rest of the substrates. This fact was pointed out by other authors when using the same yeast strain for the fermentation of enzymatic hydrolysates from olive-tree pruning [33].

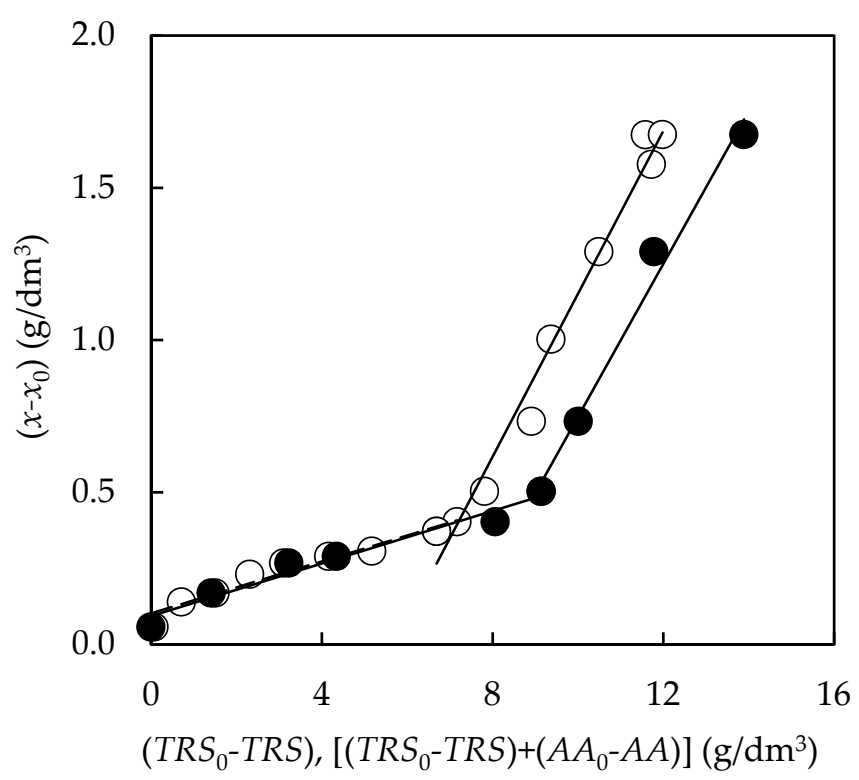

Figure 9. Biomass yield of the culture considering as substrate the total reducing sugars (TRS) (black points) or the sum of total reducing sugars and acetic acid $(A A)$ (open points). 


\subsubsection{Formation of Bioproducts}

To assess the ethanol production, it was considered that the concentration of the bioethanol $(E)$ changed over fermentation according to Equation (8)

$$
\frac{E_{\mathrm{T}}}{E_{\mathrm{T}}-E}=\mathrm{A}^{t^{\mathrm{B}}}
$$

where $E_{\mathrm{T}}$ stands for the maximum attainable ethanol concentration based on the GayLussac yield, while A and B are empirical parameters. From the linearization of Equation (8), Equation (9) is obtained.

$$
\operatorname{Ln}\left[\operatorname{Ln}\left(\frac{E_{\mathrm{T}}}{E_{\mathrm{T}}-E}\right)\right]=\operatorname{Ln}(\operatorname{Ln} A)+(B \cdot \operatorname{Ln} t)
$$

It was observed that ethanol was generated differently depending on whether the yeast uptook D-glucose, which occurred in the first $31.5 \mathrm{~h}$ of the bioprocess, or the rest of the substrates (Figure 10A). From the calculated values of A and B, and applying Equation (6), it was possible to mathematically model the evolution of ethanol concentration during fermentation (Figure 10B).

On the other hand, the specific ethanol production rate was determined (differential method) from the values of A and B by applying Equation (10)

$$
q_{E}^{D}=\frac{E_{\mathrm{T}} \cdot \mathrm{B} \cdot \operatorname{Ln} \mathrm{A} \cdot t^{\mathrm{B}-1} \cdot \mathrm{A}^{-t^{\mathrm{B}}}}{x}
$$

where $x$ is the biomass concentration at a given time. The highest specific ethanol production rates calculated by the differential $\left(q_{E}^{D}\right)$ and integral $\left(q_{E}\right)$ methods of treatment of kinetic data were quite similar $(0.218$ and $0.254 \mathrm{~kg} / \mathrm{kg} \cdot \mathrm{h}$, respectively) and were achieved in the D-glucose uptake stage.

Finally, the overall yields in ethanol $\left(Y_{E / s}^{G}\right)$ and xylitol $\left(Y_{X y / s}^{G}\right)$ were calculated from the representation of the concentrations of ethanol and xylitol against the concentration of uptaken substrates (Figure 11). The overall yield in xylitol was $0.01 \mathrm{~kg}$ per $\mathrm{kg}$ of substrate, while two stages with different yields were observed for the overall ethanol yield. In the first of them, $Y_{E / s}^{G}$ reached $0.45 \mathrm{~kg}$ of ethanol per $\mathrm{kg}$ of consumed uptake, while in the second, $Y_{E / s}^{G}$ was $0.15 \mathrm{~kg}$ of ethanol per $\mathrm{kg}$ of substrate. The former ethanol yield $(0.45 \mathrm{~kg} / \mathrm{kg})$ is similar than those that can be achieved with Saccharomyces cerevisiae, the yeast that best ferments D-glucose to ethanol. S. cerevisiae reaches ethanol yields close to the maximum theoretical ethanol yield ( $0.51 \mathrm{~kg}$ ethanol $/ \mathrm{kg}$ D-glucose) [2]. Thus, an average ethanol yield of $0.49 \mathrm{~kg} / \mathrm{kg}$ glucose has been reported using the enzymatic hydrolysate from waste sorghum leaves as a substrate for fermentation with this yeast [34]. Notwithstanding, S. cerevisiae is not able to ferment pentoses (D-xylose and L-arabinose), which is its main hindrance for ethanol production from lignocellulose. These results indicate that while the efficiency in the transformation of D-glucose into ethanol is very high, the rest of the substrates (D-xylose, L-arabinose, acetic acid, etc.) are largely metabolized towards biomass production by $P$. tannophilus. Taking into account that D-glucose represents, at the beginning of fermentation, $15.5 \%$ of the total reducing sugars, an average ethanol yield of $0.20 \mathrm{~kg}$ of bioproduct per $\mathrm{kg}$ of TRS was obtained, which is equivalent to $6.4 \mathrm{dm}^{3}$ ethanol for every $100 \mathrm{~kg}$ raw material. The yields achieved in this work are similar to those described in previous works when fermenting different lignocellulose hydrolysates with P. tannophilus $[21,35]$. 


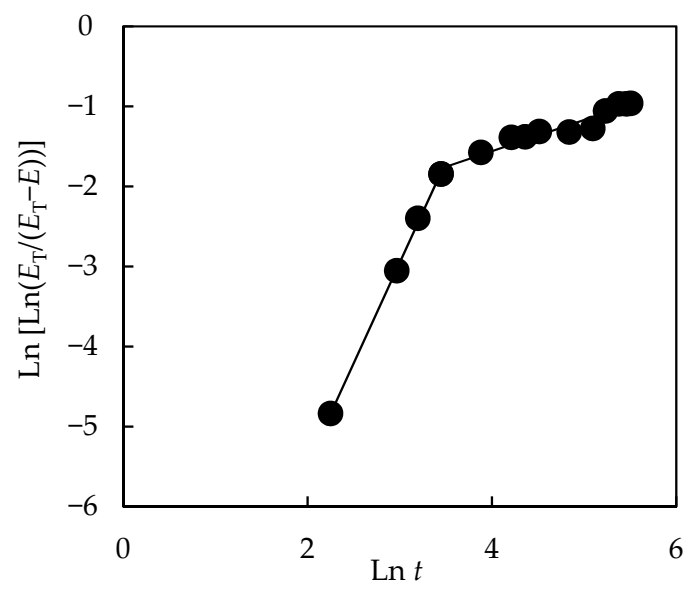

(A)

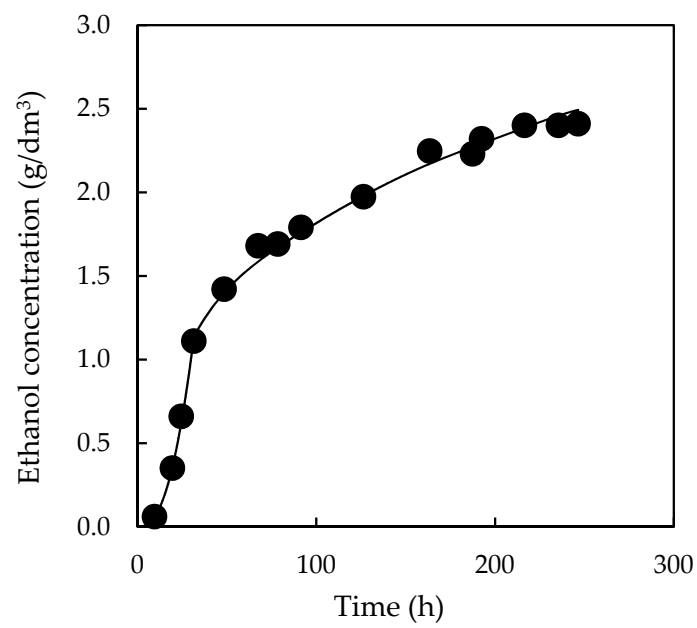

(B)

Figure 10. Ethanol production over fermentation with P. tannophilus. (A) Fit of the experimental data to Equation (8). (B) Comparison of the experimental concentrations (black points) with those predicted by model (line).

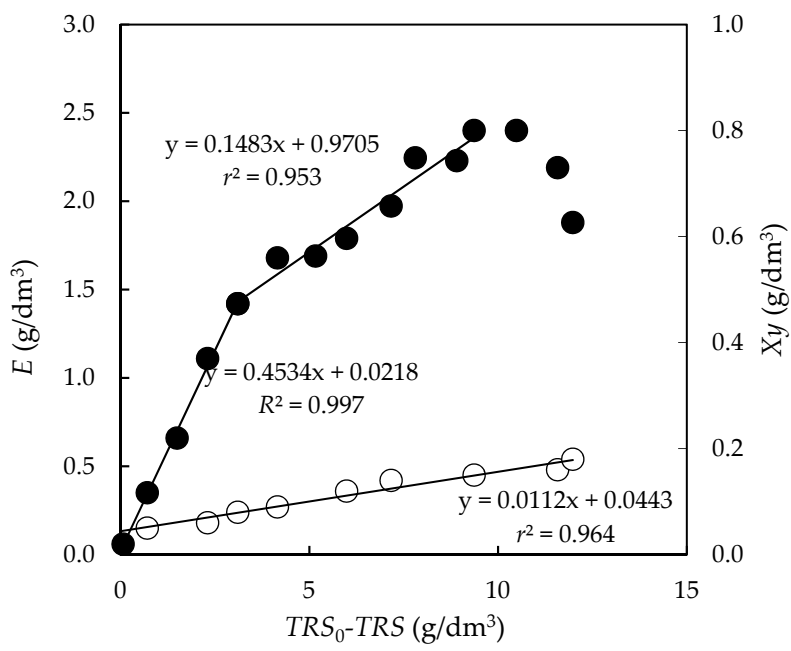

Figure 11. Overall ethanol (black circles) and xylitol (open circles) for the fermentation with P. tannophilus. 


\section{Conclusions}

The main conclusions derived from the experimental work carried out are:

(a) The conversion of olive stones into ethanol can be performed by applying a process with the following stages: reduction in the particle size of the biomass, pre-treatment with liquid hot water under pressure (LHW), enzymatic hydrolysis of the pre-treated slurry and, finally, the fermentation of enzymatic hydrolysate with the non-traditional yeast P. tannophilus. In this scheme, the D-glucose production in the enzymatic stage is strongly dependent on the severity of the LHW pre-treatment, as well as on the loading and nature of the enzymes used;

(b) The generation of D-glucose over the enzymatic hydrolysis of the pre-treated cellulose was modelled using the Chrastil's model, which provides, through parameter $n$, the resistance of the solid structure to enzyme diffusion. In this sense, a relationship between the pre-treatment severity factor $\left(\log R_{0}\right)$ and the value of the parameter $n$ has been established for the first time. In the case of olive stones, $n$ reaches values close to 1 for $\log R_{0}=4.39$;

(c) Two different stages were observed for both substrate uptake and biomass, and ethanol and xylitol production during the fermentation of the enzymatic hydrolysates with P. tannophilus. In the first stage, the yeast quickly assimilated the D-glucose from the culture producing ethanol and cellular material (biomass) with yields of 0.45 (close to the maximum theoretical ethanol yield) and $0.11 \mathrm{~kg}$ per $\mathrm{kg}$ uptaken substrate, respectively. In the second, slower stage, from $31.5 \mathrm{~h}$ of starting the culture, acetic acid and reducing sugars other than D-glucose were consumed, leading to an ethanol yield of $0.15 \mathrm{~kg}$ per $\mathrm{kg}$ of uptaken substrate, much lower than in the stage of D-glucose uptake.

Author Contributions: M.C. performed the experimental work and the analysis of the data, and contributed to the aspects related to the design of figures and writing the initial draft paper; J.F.G.M. performed the English translation, text and figures formatting and revision of the paper; V.B. contributed to the analysis of the data and revision of the paper. S.S. provided the funding, performed the experimental design, and contributed to the revision of the paper. All authors have read and agreed to the published version of the manuscript.

Funding: This work was funded the projects 01272/2005 and AGR/6509 granted by Andalusia Regional Government (Spain).

Acknowledgments: The authors wish to thank the olive oil mil S.C.A. San Juan (Spain) for providing the olive stones used in this research.

Conflicts of Interest: The authors declare no conflict of interest.

\section{References}

1. Rodríguez, G.; Lama, A.; Rodríguez, R.; Jiménez, A.; Guillén, R.; Fernández-Bolaños, J. Olive stone an attractive source of bioactive and valuable compounds. Bioresour. Technol. 2008, 99, 5261-5269. [CrossRef] [PubMed]

2. García Martín, J.F.; Cuevas, M.; Feng, C.H.; Mateos, P.Á.; García, M.T.; Sánchez, S. Energetic valorisation of olive biomass: Olive-tree pruning, olive stones and pomaces. Processes 2020, 8, 511. [CrossRef]

3. Mata-Sánchez, J.; Pérez-Jiménez, J.A.; Díaz-Villanueva, M.J.; Serrano, A.; Núñez-Sánchez, N.; López-Giménez, F.J. Statistical evaluation of quality parameters of olive stone to predict its heating value. Fuel 2013, 113, 750-756. [CrossRef]

4. Ministerio de Agricultura Pesca y Alimentación. Encuesta Sobre Superficies y Rendimientos Cultivos. Available online: https:/ / servicio.mapama.gob.es / (accessed on 15 January 2021).

5. Cuevas, M.; Sánchez, S.; Bravo, V.; García, J.F.; Baeza, J.; Parra, C.; Freer, J. Determination of optimal pre-treatment conditions for ethanol production from olive-pruning debris by simultaneous saccharification and fermentation. Fuel 2010, 89, $2891-2896$. [CrossRef]

6. Cuevas, M.; Saleh, M.; García-Martín, J.F.; Sánchez, S. Acid and enzymatic fractionation of olive stones for ethanol production using Pachysolen tannophilus. Processes 2020, 8, 195. [CrossRef]

7. Saleh, M.; Cuevas, M.; García, J.F.; Sánchez, S. Valorization of olive stones for xylitol and ethanol production from dilute acid pretreatment via enzymatic hydrolysis and fermentation by Pachysolen tannophilus. Biochem. Eng. J. 2014, 90, 286-293. [CrossRef]

8. Cuevas, M.; Sánchez, S.; García, J.F.; Baeza, J.; Parra, C.; Freer, J. Enhanced ethanol production by simultaneous saccharification and fermentation of pretreated olive stones. Renew. Energy 2015, 74, 839-847. [CrossRef] 
9. Cuevas, M.; Sánchez, S.; Bravo, V.; Cruz, N.; García, J.F. Fermentation of enzymatic hydrolysates from olive stones by Pachysolen tannophilus. J. Chem. Technol. Biotechnol. 2009, 84, 461-467. [CrossRef]

10. Cuevas, M.; García, J.F.; Cruz, N.; Sanchez, S. Generation of D-xylose by hydrothermal treatment of olives endocarps and enzymatic hydrolysis of oligosaccharides. Afinidad 2013, 70, 99-106.

11. Cuevas, M.; García, J.F.; Hodaifa, G.; Sánchez, S. Oligosaccharides and sugars production from olive stones by autohydrolysis and enzymatic hydrolysis. Ind. Crops Prod. 2015, 70, 100-106. [CrossRef]

12. Fernández-Bolaños, J.; Felizón, B.; Heredia, A.; Rodríguez, R.; Guillén, R.; Jiménez, A. Steam-explosion of olive stones: Hemicellulose solubilization and enhancement of enzymatic hydrolysis of cellulose. Bioresour. Technol. 2001, 79, 53-61. [CrossRef]

13. Fernández-Bolaños, J.; Felizón, B.; Heredia, A.; Guillén, R.; Jiménez, A. Characterization of the lignin obtained by alkaline delignification and of the cellulose residue from steam-exploded olive stones. Bioresour. Technol. 1999, 68, 121-132. [CrossRef]

14. Cano, M.E.; García-Martin, A.; Morales, P.C.; Wojtusik, M.; Santos, V.E.; Kovensky, J.; Ladero, M. Production of oligosaccharides from agrofood wastes. Fermentation 2020, 6, 31. [CrossRef]

15. García, J.F.; Sánchez, S.; Bravo, V.; Rigal, L.; Cuevas, M. Acid hydrolysis of olive-pruning debris for D-xylose production. Collect Czechoslov. Chem. Commun. 2008, 73, 637-648. [CrossRef]

16. Overend, R.P.; Chornet, E. Fractionation of lignocellulosics by steam-aqueous pretreatments. Philos. Trans. R. Soc. London. Ser. A Math. Phys. Sci. 1987, 321, 523-536.

17. Fillat, Ú.; Ibarra, D.; Eugenio, M.E.; Moreno, A.D.; Tomás-Pejó, E.; Martín-Sampedro, R. Laccases as a potential tool for the efficient conversion of lignocellulosic biomass: A review. Fermentation 2017, 3, 17. [CrossRef]

18. Offei, F.; Mensah, M.; Thygesen, A.; Kemausuor, F. Seaweed bioethanol production: A process selection review on hydrolysis and fermentation. Fermentation 2018, 4, 99. [CrossRef]

19. Chrastil, J. Enzymic product formation curves with the normal or diffusion limited reaction mechanism and in the presence of substrate receptors. Int. J. Biochem. 1988, 20, 683-693. [CrossRef]

20. Carrillo, F.; Lis, M.J.; Colom, X.; López-Mesas, M.; Valldeperas, J. Effect of alkali pretreatment on cellulase hydrolysis of wheat straw: Kinetic study. Process Biochem. 2005, 40, 3360-3364. [CrossRef]

21. Converti, A.; Del Borghi, M. Inhibition of the fermentation of oak hemicellulose acid-hydrolysate by minor sugars. J. Biotechnol. 1998, 64, 211-218. [CrossRef]

22. García Martín, J.F.; Cuevas, M.; Bravo, V.; Sánchez, S. Ethanol production from olive prunings by autohydrolysis and fermentation with Candida tropicalis. Renew. Energy 2010, 35, 1602-1608. [CrossRef]

23. Trinder, P. Determination of glucose in blood using glucose oxidase with an alternative oxygen acceptor. Ann. Clin. Biochem. Int. J. Lab. Med. 1969, 6, 24-27. [CrossRef]

24. Bergmeyer, H.U.; Möllering, H. Acid acetic. In Methods of Enzymatic Analysis; Bergmeyer, H.U., Ed.; Verlag Chemie: Weinheim, Germany, 1974; pp. 1520-1528.

25. Beutler, H.O. Ethanol. In Methods of Enzymatic Analysis; Bergmeyer, H.U., Ed.; Verlag Chemie: Weinheim, Germany, 1984; pp. 598-606.

26. Beutler, H.O.; Becker, J. Enzymatische Bestimmung von D sorbit und Xylit in Lebensmitteln. Dtsch. Leb. 1977, 6, $182-187$.

27. Bravo, V.; Camacho, F.; Sánchez, S.; Castro, E. Influence of the concentrations of D-xylose and yeast extract on ethanol production by Pachysolen tannophilus. J. Ferment. Bioeng. 1995, 79, 566-571. [CrossRef]

28. Yang, M.; Zhang, W.; Rosentrater, K.A. Anhydrous ammonia pretreatment of corn stover and enzymatic hydrolysis of glucan from pretreated corn stover. Fermentation 2017, 3, 9. [CrossRef]

29. Oliva, J.M.; Negro, M.J.; Manzanares, P.; Ballesteros, I.; Chamorro, M.Á.; Sáez, F.; Ballesteros, M.; Moreno, A.D. A sequential steam explosion and reactive extrusion pretreatment for lignocellulosic biomass conversion within a fermentation-based biorefinery perspective. Fermentation 2017, 3, 15. [CrossRef]

30. Carvalho, M.L.; Sousa, R.; Rodríguez-Zúñiga, U.F.; Suarez, C.A.G.; Rodrigues, D.S.; Giordano, R.C.; Giordano, R.L.C. Kinetic study of the enzymatic hydrolysis of sugarcane bagasse. Braz. J. Chem. Eng. 2013, 30, 437-447. [CrossRef]

31. Sánchez, S.; Bravo, V.; García, J.F.; Cruz, N.; Cuevas, M. Fermentation of D-glucose and D-xylose mixtures by Candida tropicalis NBRC 0618 for xylitol production. World J. Microbiol. Biotechnol. 2008, 24, 709-716. [CrossRef]

32. García, J.F.; Sánchez, S.; Bravo, V.; Cuevas, M.; Rigal, L.; Gaset, A. Xylitol production from olive-pruning debris by sulphuric acid hydrolysis and fermentation with Candida tropicalis. Holzforschung 2011, 65, 59-65. [CrossRef]

33. Romero, I.; Sánchez, S.; Moya, M.; Castro, E.; Ruiz, E.; Bravo, V. Fermentation of olive tree pruning acid-hydrolysates by Pachysolen tannophilus. Biochem. Eng. J. 2007, 36, 108-115. [CrossRef]

34. Rorke, D.C.S.; Kana, E.B.G. Kinetics of bioethanol production from waste sorghum leaves using Saccharomyces cerevisiae BY4743. Fermentation 2017, 3, 19. [CrossRef]

35. Sanchez, G.; Pilcher, L.; Roslander, C.; Modig, T.; Galbe, M.; Liden, G. Dilute-acid hydrolysis for fermentation of the Bolivian straw material Paja Brava. Bioresour. Technol. 2004, 93, 249-256. [CrossRef] [PubMed] 